\title{
The Influence of Ethnicity in the Relationship between Sedentary Screen Time and Left Ventricular Mass: Insights from the MAG-SALVAGES
}

\author{
Charifa Annis ${ }^{1}$, Bernard Kianu Phanzu' ${ }^{2}$, Moussa Sidibe1, Mustapha El Hattaoui ${ }^{1}$,

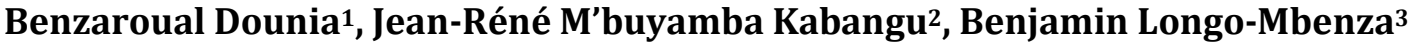 \\ ${ }^{1}$ Unit of Cardiology, CHU Mohammed VI, Cady Ayyad University, Marrakech, Kingdom of Morocco \\ ${ }^{2}$ Unit of Cardiology, University Hospital of Kinshasa, Kinshasa, Democratic Republic of Congo \\ ${ }^{3}$ Faculty of Health Sciences, Walter Sisulu University, Mthatha, Republic of South Africa \\ Email: doctorkianu@gmail.com
}

How to cite this paper: Annis, C., Phanzu, B.K., Sidibe, M., El Hattaoui, M., Dounia, B., Kabangu, J.-R.M. and Longo-Mbenza, B. (2017) The Influence of Ethnicity in the Relationship between Sedentary Screen Time and Left Ventricular Mass: Insights from the MAG-SALVAGES. World Journal of Cardiovascular Diseases, 7, 11-23.

https://doi.org/10.4236/wjcd.2017.72002

Received: December 15, 2016

Accepted: February 12, 2017

Published: February 15, 2017

Copyright $(9) 2017$ by authors and Scientific Research Publishing Inc. This work is licensed under the Creative Commons Attribution International License (CC BY 4.0).

http://creativecommons.org/licenses/by/4.0/

\begin{abstract}
Background: The influence of race/ethnicity on the relationship between sedentary screen time and left ventricular mass has been recently suggested, but remains a subject of debate, and has never been explored in Africa. Purpose: To determine whether there is a racial/ethnic influence on the relationship between sedentary screen time and left ventricular mass in MAGhreb and Sub Saharan Africa Left-Ventricul ArGEometry Study (MAG-SALVAGES) participants. Methods: 100 blacks sub-Saharan African and 187 white Maghreb aged 18 - 55 years underwent an interview on their behavioral measures, physical activity and eating habits. Their left ventricular mass has also been measured by a resting transthoracic echography according to the American Society of Echography. Generalized linear models evaluated a test-for-trend across higher levels of sedentary screen time in progressive models with left ventricular measurements as dependent variables. The study population was stratified into quartiles of sedentary screen time (separately for whites and blacks) and examined the joint association of sedentary screen time and LVM within quartiles of physical activity. Results: Among White Maghreb, higher screen time was associated with smaller left ventricular mass $(P<0.001)$. This association persisted when adjusting for age, gender, heart rate, waist circumference, waistto-hip ratio, systolic blood pressure QRS duration, TAPS and PAPS. Whereas, in blacks sub-Saharan African, the left ventricular mass was not associated with sedentary screen time. Conclusions: Sedentary screen time is associated with smaller left ventricular mass in White Maghreb, not in black sub-Saharan African. The lack of association in blacks supports a potential qualitative difference in the cardiovascular consequences of sedentary screen based behavior.
\end{abstract}




\section{Keywords}

Left Ventricular Mass, Sedentary, Ethnicity, White Maghreb, Black Sub-Saharan Africa

\section{Introduction}

Many of the modern diseases are corollaries of profound changes that accompanied the 45,000 years of evolution from Homo sapiens sapiens, to whom physical activity was the pledge of survival [1], to the today human who uses more neurons than muscles to live and survive, and therefore, has reduced physical activity and increased energy intake. Nowadays, humans have the unfortunate luck of having more opportunities for being sedentary. This is the so called sedentary behavior, which is defined as activities that do not increase energy expenditure substantially above the resting level such as sitting, watching TV, and playing PC/video games. This situation is known to be linked with increased cardiovascular disease morbidity and mortality. The majority of prospective studies of sedentary screen time (SST) has shown that greater sedentary time is associated with an increased risk of fatal and non-fatal CVD [2]-[9].

Sedentary behavior is responsible for the occurrence of several cardiovascular risk factors including obesity, insulin resistance, and high blood pressure. These factors in turn contribute to the occurrence of left ventricular hypertrophy (LVH). The left ventricular mass (LVM) correlates closely with the incidence of heart failure, stroke, coronary disease [10] and overall mortality [11]. So one pathway through which sedentary behavior may contribute to cardiovascular disease is through an impact on left ventricular mass. However the link between SST and LVM remains a controversial issue. Data from the National Health and Nutritional Examination Survey (NHANES) suggests that sedentary time is associated with cardiovascular risk factors and obesity in whites but not blacks [12]. Bethany et al. found that SST is associated with greater LVM in white not in Blacks [13]. This was an American cohort of Blacks and Whites. This issue has never been addressed in an African population.

\section{Methods}

\subsection{Study Design}

\section{Study Population and Settings}

The MAG-SALVAGES (MAGhreb and Sub-Saharan Africa Left-Ventricul ArGEometry Study) is a population-based survey conducted in Marrakech, Morocco, from November 2015 to January 2016. It recruited Black Sub-Saharan African (BSSA) and white Maghreb student population living in Marrakech.

\subsection{Recruitment Strategy}

\subsubsection{Investigators}

The investigation team consisted of senior residents of the Cardiology Unit of 
Cady Ayyad University. The principal investigators (KPB and AS) introduced the study, explained the goals, described how the study was to be performed, and described the responsibilities of each investigator. The principal investigators attended staff meetings to discuss and answer any questions the investigator team had. A pre-test session was conducted asking a dozen students to evaluate the questionnaire, to test the appropriateness of the data collection sheet, and to assess the ability of the investigators to apply the protocol correctly.

\subsubsection{Study Participants}

The BSSA participants were all members of the The CESAM (Confédérationd' Etudiantset Stagiaires Africains de Marrakech). This is a cultural association that includes all BSSA students in Marrakech. It provided us with the names and addresses of BSSA students. Recruitment of Maghreb students was facilitated by the Secretary General of the Cady Ayyad University Students Office. Students were randomly chosen from the student's office and were invited to participate in the study.

\subsubsection{Eligibility Criteria}

The subjects recruited for the MAG-SALVAGES were asymptomatic students aged 18 years or older, regardless of their level of study (undergraduate, graduate, post-graduate, or doctoral). Participants with significant valvulopathy, who had poor echogenicity to the extent that echocardiographic parameters could not be measured, or who did not complete the planned investigations were excluded.

\subsection{Data Collection}

\section{Interviews}

Participants were interviewed using a questionnaire in a 20 -minute session. Items asked included demographic characteristics (sex, age, ethnic group, and duration of residence in Marrakech for BSSA), lifestyle (diet, physical activity, smoking status, and alcohol intake), and personal medical history (hypertension, diabetes mellitus, hypercholesterolemia, and hyperuricemia). All these data were based on self-report. Participants were asked about their intake of fruits, vegetables, and fats, with regular consumption of fruits and vegetables defined as at least four days a week. Physical activity was assessed using the WHO/GPAQ [14]. The participants were categorized as either active or inactive based on whether they did or did not engage in moderate or vigorous exercise, with sedentary defined as sitting more than 7 hours daily. The categories for smoking were current smoker (defined as smoking at least one cigarette within the past month) or nonsmoker/former smoker (the latter defined as having quit smoking more than 3 month prior to the study). Alcohol consumption was categorized as excessive drinking ( $\geq 3$ units/day for men and $\geq 2$ units/day for women) or nondrinking/moderate drinking ( $\leq 2$ units/day for men and $\leq 1$ unit/day for women).

\subsection{Clinical Examination}

\subsubsection{Physical Measurements}

Participants were weighed without heavy clothing to the nearest $0.1 \mathrm{~kg}$ using a 
digital impedancemeter scale. The same apparatus also provided body composition (fat mass (\%), total body water (\%), lean body mass (\%), bone mass (kg), and daily energy expenditure (Kcal). Height was measured to the nearest $0.1 \mathrm{~cm}$ using a mounted stadiometer. Body mass index (BMI) was calculated as weight in kilograms $(\mathrm{kg})$ divided by height in meters squared $\left(\mathrm{m}^{2}\right)$. Waist circumference (WC) was measured using a flexible tape measure, with the participant standing, and after gentle expiration, at a point midway between the lower costal margin and the upper border of the iliac crest. Hip circumference was measured at the widest point of the buttocks. The waist-to-hip ratio (WHR) and the waist-toheight ratio (WHeR) were calculated. Body surface area (BSA) was calculated $\mathrm{m}^{2}$ $=0.007184 \times$ height $(\mathrm{cm}) 0.725 \times$ weight $(\mathrm{kg}) 0.425$. Total obesity was defined as a BMI greater than $30.0 \mathrm{~kg} / \mathrm{m}^{2}$ and abdominal obesity as $\mathrm{WC} \geq 102 \mathrm{~cm}$ in males and $\geq 88 \mathrm{~cm}$ in females.

\subsubsection{Vital Signs}

Sitting blood pressure (BP) was measured on the upper left arm non-invasively using an automated validated device (OMRON M6, HEM 7001E) with a cuff size appropriate for the arm diameter. Participants relaxed for 5 minutes in a sitting position, after which the BP was measured twice. A third measurement was required if the first two differed by at least $10 \mathrm{mmHg}$ for systolic blood pressure (SBP) and/or $5 \mathrm{mmHg}$ for diastolic blood pressure (DBP). The BP readings were averaged for analysis. The BP monitors were calibrated every morning against a standard mercury sphygmomanometer using a T-tube and applying static pressures ranging from 0 to $250 \mathrm{mmHg}$ at $50-\mathrm{mmHg}$ intervals. A device that deviated by $5 \mathrm{mmHg}$ or more was replaced by a new one. Pulse pressure (PP) and mean arterial pressure (MAP) were calculated as follows: $\mathrm{PP}=\mathrm{SPB}-\mathrm{DBP}$; MAP $=\mathrm{DBP}+\mathrm{PP} / 3$

\subsubsection{ECG Measurements and Interpretation}

A simultaneous 12-lead resting electrocardiogram (ECG) was recorded on an automated machine (EAS/OTE-ACTA Cardiograph, Italy) at a sampling frequency of $500 \mathrm{~Hz}$ over $10 \mathrm{~s}$ with a resolution of $5 \mathrm{mV}$ and stored digitally.

To minimize inter or intraobserver variability and avoid variation in the amplitude and duration of waves and spaces from beat to beat, all ECGs was processed with the MEANS program (Welch Allyn, Inc. USA) to obtain ECG measurements and diagnostics interpretations.

\subsubsection{Echocardiography Measurements}

One or the other of the principal investigators performed echocardiography using an HD 15 Sonos 5500 (Phillips Medical Systems, Andover, MA, USA) ultrasound system equipped with $2.5,3.5$, and $5.0 \mathrm{MHz}$ transducers. Three measurements were taken for each variable with the mean value used in analysis. Image was stored for subsequent validation by a team of three skilled training specialists of the CHU Mohammed VI echocardiography laboratory. Measurements were taken according to the 2015 American Society of Echocardiography and the European Association of Cardiovascular Imaging updated guidelines for cardiac 
chamber quantification [15]. Two-dimensionally guided M-mode echocardiography was performed on a parasternal long-axis view. Interventricular septum (IVS) thickness in diastole (IVSd) in $\mathrm{mm}$, left ventricular posterior wall (PW) thickness in diastole (LVPWd) in mm, and left ventricular end-diastolic diameter (LVEDd) in mm were measured at end-diastole at a level just below the mitral valve leaflets. Simultaneous ECG was used to correlate measurements with the cardiac cycle. Diastolic wall thickness was measured at the onset of the QRS wave. LVM was calculated according to the American Society of Echocardiography simplified cubed equation linear method using the following equation: LVM $($ grams $)=0.8 \times 1.04 \times[($ LVEDd + IVSd + LVPWd $) 3-($ LVEDd $) 3]+0.6 \mathrm{~g}$. LVM was indexed by BSA and by height2.7. LVM was considered normal when $\leq 115 \mathrm{~g} / \mathrm{m}^{2}$ or $\leq 48 \mathrm{~g} / \mathrm{m} 2.7$ in males and $\leq 95 \mathrm{~g} / \mathrm{m}^{2}$ or $\leq 44 \mathrm{~g} / \mathrm{m} 2.7$ in females. LVH was defined as LVM exceeding those values. The relative wall thickness (RWT) of the left ventricle $(\mathrm{LV})$ was calculated as $(2 \times \mathrm{LVPWd}) / \mathrm{LVEDd}$. LV geometric patterns were defined as follows: normal geometry (normal LVM and RWT $\leq 0.42$ ), concentric remodeling (normal LVM and RWT > 0.42), concentric hypertrophy (LVH and RWT $>0.42$ ), and eccentric hypertrophy (LVH and RWT $\leq 0.42$ ).

To analyze LV systolic function, the ejection fraction (stroke volume/diastolic volume $\times 100$ ), percentage of LV systolic shortening (\%) ([diastolic diameter systolic diameter]/diastolic diameter $\times 100$ ] and cardiac output (stroke volume $\times$ heart rate) were calculated. Stroke volume was calculated as $2 \pi \mathrm{D} / 4 \times$ velocity time integral, where $\mathrm{D}$ is the diameter of the aortic annulus measured in the left parasternal long-axis view at mid-systole from inner edge to inner edge.

The presence or absence of valve disease was detected by visual assessment in 2D and color Doppler in the left parasternal long-axis and apical four-chamber views.

\subsubsection{Statistics}

After encoding and validation, the data were entered in a computer using Epi-InfoTM statistical software, version 7.1.2.0 (Atlanta, USA)

(https://www.cdc.gov/epiinfo/index.html). Results for each BSSA were compared with two Maghreb subjects matched for age ( \pm 1 year) and sex. Continuous variables are expressed as means and categorical variables as percentages. In order to compare means in independent samples, Student's t test or the MannWhitney test was used. Comparison of the means of three or more groups was performed with analysis of variance. The Tukey test for multiple comparisons was used to distinguish the different groups. For variables not fitting a normal distribution, the Kruskal-Wallis analysis of variance and the corresponding test of multiple comparisons were used. Pearson's correlation coefficient (r) was used to assess any significant association between two continuous variables. To compare proportions, the chi-square test or Fisher exact test was used. Frequency distributions of LVM dichotomized by ethnicity were constructed. Comparisons were made between BSSA and Maghreb for all parameters. When differences were observed on univariate analysis, the effect of potential confounders was studied by adjustment with multivariate linear regression. A significance 
level of 5\% was adopted. IBM SPSS version 21

(http://www.ibm.com/support/knowledgecenter/SSLVMB_21.0.0) was used for statistical calculations.

\subsection{Ethics and Consent}

This research was conducted in strict compliance with the recommendations of the Helsinki Declaration III. All respondents were briefed on the conclusions drawn from their investigations. Approval was obtained from the ethics committee of Cady Ayyad University. Each participant provided written informed consent.

\subsubsection{Statistics}

Participant characteristics according to SST were described using means and percentages as appropriate. Left ventricular measurements are presented as adjusted least squares means with $95 \%$ confidence intervals. Generalized linear models evaluated a test-for-trend across higher levels of sedentary screen time in progressive models with left ventricular measurements as dependent variables. Cutpoints for sedentary screen time categories were defined a priori to isolate extreme individuals ( $1-4 \mathrm{~h}, 5-9 \mathrm{~h}$ and $\geq 10$ hour of screen time/day). We detected a significant interaction between race and sedentary time for LVM $(\mathrm{P}=0$ $<0.001$ ), and thus report results separately by race. No gender interaction was detected for the relationship between sedentary time and LVM ( $\mathrm{P}=0.184)$.

To examine whether the association between SST and LVM was consistent across the range of leisure-time activity, the study population were stratified into quartiles of sedentary screen time (separately for whites and blacks) and examined the joint association of sedentary screen time and LVM within quartiles of physical activity.

\subsubsection{Ethics and Consent}

This Work Research has been conducted in strict compliance with the recommendations of the Helsinki Declaration III. The questionnaire was administered anonymously, and information obtained in the interview / anamnesis and clinical and paraclinical examination was transcribed into pre-established survey forms and pre-coded in compliance with the confidentiality and privacy of the participants. All respondents have been briefed on the conclusions drawn from their investigations.

Ethical approval was obtained from the ethics committees of Cady Ayyad University. Each participant provided written informed consent for his participation in the study.

\section{Results}

A total of 302 participants were initially recruited, 102 BSSA and 200 Maghreb. Thirteen participants were excluded because of poor echogenicity (three female Maghreb), significant valvular disease (four female Maghreb), refusal to undergo the ECG and echocardiography for modesty reasons (two female Maghreb), and failure to appear for the echocardiography (two male BSSA and two male Magh- 
reb). The final analysis therefore comprised 289 participants, 100 BSSA and 189 Maghreb.

Overall, the rate of physical inactivity was higher in SSA (39\%) than in Maghreb $(24.9 \%)(p=0.018)$. The rate of physical activity was higher in Maghreb $(75.1 \%)$ than in SSA $(61.0 \%)(p=0.015)$. The rate of sedentary was similar in the two ethnic groups: $30.7 \%$ in Maghreb versus $29 \%$ in the SSA ( $p=0.801$ ) (Table 1). BSSA were significantly taller than the Maghreb. Maghreb had a greater mean BMI, WC, HC, SBP, PP, and fat mass than BSSA (Table 2).

Total and abdominal obesity were significantly more prevalent among Maghreb than among BSSA. QRS and QTc duration were the only ECG parameters that differed between the two populations, with a significantly longer average duration among Maghreb (Table 3). LVEDd was significantly higher among Maghreb than among BSSA, but this difference disappeared when indexed to BSA (Table 3). LVPWd was significantly greater among BSSA than among Maghreb. This difference persisted after adjustment for confounding factors (BMI, WC, HR, and fat mass). The differences observed for all other echocardiographic parameters were not statistically significant, including LVM for which the means of the two groups were similar regardless of the mode of Indexing.

Table 1. Characteristics of the study population as a whole and stratified according to ethnicity.

\begin{tabular}{|c|c|c|c|c|}
\hline Variables & $\begin{array}{l}\text { All participants } \\
n=289\end{array}$ & $\begin{array}{c}\text { BSSA } \\
\mathrm{n}=100\end{array}$ & $\begin{array}{c}\text { Maghreb } \\
\mathrm{n}=189\end{array}$ & $\mathrm{p}$ \\
\hline \multicolumn{5}{|l|}{$\begin{array}{l}\text { Demographic } \\
\text { characteristics }\end{array}$} \\
\hline Age (years) & $29.8 \pm 11.2$ & $28.5 \pm 10.7$ & $30.4 \pm 11.5$ & 0.171 \\
\hline Gender & & & & 0.121 \\
\hline Male & $173(59.9)$ & $65(65.0)$ & $108(57.1)$ & \\
\hline Female & $116(40.1)$ & $35(35.0)$ & $81(42.9)$ & \\
\hline Place of birth & & & & $<0.0001$ \\
\hline SSA & $99(34.4)$ & $98(98.0)$ & $1(0,5)$ & \\
\hline Maghreb & $189(65.6)$ & $2(2.0)$ & $187(99.5)$ & \\
\hline \multicolumn{5}{|l|}{ Life style characteristics } \\
\hline \multicolumn{5}{|c|}{ Regular consumption of } \\
\hline Fruits & $162(56.1)$ & $39(39.0)$ & $123(65.1)$ & $<0.0001$ \\
\hline Vegetables & $225(77.9)$ & $68(68.0)$ & $157(83.1)$ & 0.005 \\
\hline Fats & $276(95.3)$ & $93(93.0)$ & $183(96.8)$ & 0.201 \\
\hline \multicolumn{5}{|l|}{ Smoking/Alcohol } \\
\hline Currentsmoker & $18(6.2)$ & $6(6.0)$ & $12(6.3)$ & 0.564 \\
\hline Excessive drinker & $8(2.8)$ & $2(2.0)$ & $6(3.2)$ & 0.436 \\
\hline \multicolumn{5}{|l|}{ Physical activity } \\
\hline Active & $203(70.2)$ & $61(61.0)$ & $142(75.1)$ & 0.015 \\
\hline Inactive & $86(29.8)$ & $39(39.0)$ & $47(24.9)$ & 0.018 \\
\hline sedentary & $87(30.1)$ & $19(29.0)$ & $58(30.7)$ & 0.801 \\
\hline
\end{tabular}

BSSA: Black Sub-Saharan African, SSA: Sub-Saharan Africa. 
Table 2. Physical variables and cardiovascular risk factors of the study population as a whole and stratified according to the ethnicity.

\begin{tabular}{ccccc}
\hline Variables & All participants & BSSA & Maghreb & p \\
\hline Weight(kg) & $73.3 \pm 14.9$ & $72.2 \pm 13.2$ & $73.9 \pm 15.8$ & 0.368 \\
Height $(\mathrm{cm})$ & $168.1 \pm 9.8$ & $169.7 \pm 8.5$ & $167.2 \pm 10.3$ & 0.039 \\
BMI $\left(\mathrm{kg} / \mathrm{m}^{2}\right)$ & $25.9 \pm 5.5$ & $24.5 \pm 4.6$ & $26.7 \pm 5.7$ & 0.001 \\
WC $(\mathrm{cm})$ & $\mathbf{8 6 . 3} \pm 14.5$ & $\mathbf{8 2 . 4} \pm 15.2$ & $\mathbf{8 8 . 4} \pm 13.7$ & 0.001 \\
HC (cm) & $99.6 \pm 10.6$ & $96.3 \pm 9.4$ & $101.4 \pm 10.7$ & $<0.0001$ \\
WHR (cm) & $0.87 \pm 0.12$ & $0.86 \pm 0.17$ & $0.87 \pm 0.08$ & 0.399 \\
WHeR (cm) & $0.45 \pm 0.09$ & $0.41 \pm 0.06$ & $0.50 \pm 0.08$ & 0.031 \\
SBP (mmHg) & $119.4 \pm 15.1$ & $116.6 \pm 14.6$ & $120.9 \pm 15.2$ & 0.020 \\
DBP (mmHg) & $77.2 \pm 10.1$ & $76.4 \pm 10.4$ & $77.6 \pm 10.0$ & 0.316 \\
PP (mmHg) & $42.2 \pm 11.7$ & $40.2 \pm 11.1$ & $43.3 \pm 11.9$ & 0.035 \\
MBP (mmHg) & $91.3 \pm 10.7$ & $89.8 \pm 10.7$ & $92.1 \pm 10.6$ & 0.084 \\
HR (bpm) & $72.7 \pm 12.9$ & $71.5 \pm 12.0$ & $73.4 \pm 13.4$ & 0.227 \\
Fat mass $(\%)$ & $20.9 \pm 12.2$ & $17.4 \pm 9.2$ & $22.8 \pm 13.1$ & $<0.0001$ \\
Lean mass (\%) & $29.6 \pm 4.5$ & $29.6 \pm 4.3$ & $29.6 \pm 4.7$ & 0.972 \\
CVRF & & & & \\
HTN & $9(3.1)$ & $3(3.0)$ & $6(3.2)$ & 0.893 \\
DM1 & $1(0.3)$ & $0(0.0)$ & $1(0.5)$ & 0.654 \\
DM2 & $5(1.7)$ & $1(1.0)$ & $4(2.1)$ & 0.441 \\
Total obesity & $63(21.8)$ & $15(15.0)$ & $48(25.4)$ & $<0.0001$ \\
Abdominal obesity & $64(22.1)$ & $14(14.0)$ & $50(26.5)$ & 0.013 \\
\hline
\end{tabular}

BSSA: Black Sub-Saharan African, BMI: body mass index, WC: waist circumference, HC: hip circumference, WHC: waist-to-hipratio, WHeR = waist-to-height ratio, SBP: systolic blood pressure, DBP: diastolic blood pressure, PP: pulse pressure, MBP: mean blood pressure, HR: heart rate, FM: fat mass, CVRF: cardiovascular risk factor, DM1:type 1 diabetes mellitus, DS2:type 2 diabetes mellitus.

Table 3. Electrocardiographic and echocardiographic characteristics.

\begin{tabular}{|c|c|c|c|c|}
\hline Variable & All participants & BSSA & Maghreb & $\mathrm{p}$ \\
\hline $\mathrm{PR}(\mathrm{msec})$ & $145.9 \pm 27.5$ & $146.2 \pm 23.2$ & $145.8 \pm 29.6$ & 0.901 \\
\hline QRS (msec) & $94.7 \pm 23.2$ & $90.2 \pm 20.5$ & $97.1 \pm 24.2$ & 0.016 \\
\hline QTc duration (msec) & $401.5 \pm 40.1$ & $394.1 \pm 33.6$ & $405.4 \pm 42.7$ & 0.023 \\
\hline LVEDd (mm) & $48.2 \pm 4.8$ & $47.1 \pm 5.1$ & $48.9 \pm 4.6$ & 0.004 \\
\hline LVEDd/BS $\left(\mathrm{mm} / \mathrm{m}^{2}\right)$ & $25.6 \pm 6.0$ & $26.2 \pm 2.9$ & $25.3 \pm 7.2$ & 0.218 \\
\hline LVEDs (mm) & $30.3 \pm 4.1$ & $29.9 \pm 4.2$ & $30.6 \pm 4.1$ & 0.185 \\
\hline LVPWd (mm) & $8.1 \pm 1.3$ & $8.3 \pm 1.2$ & $7.9 \pm 1.3$ & 0.011 \\
\hline IVSd (mm) & $8.2 \pm 1.3$ & $8.4 \pm 1.3$ & $8.2 \pm 1.3$ & 0.187 \\
\hline $\operatorname{LVM}(\mathrm{g})$ & $133.7 \pm 36.1$ & $132.7 \pm 37.0$ & $134.2 \pm 35.7$ & 0.726 \\
\hline LVM/height ${ }^{2.7}$ & $33.1 \pm 9.6$ & $32.1 \pm 9.8$ & $33.6 \pm 9.5$ & 0.185 \\
\hline $\mathrm{LVM} / \mathrm{BS}\left(\mathrm{mg} / \mathrm{cm}^{2}\right)$ & $73.0 \pm 16.8$ & $73.1 \pm 17.8$ & $72.9 \pm 16.2$ & 0.922 \\
\hline $\operatorname{LVEF}(\%)$ & $65.7 \pm 7.7$ & $65.3 \pm 9.4$ & $65.9 \pm 6.6$ & 0.526 \\
\hline
\end{tabular}

BSSA: Black Sub-Saharan African. PR: PRinterval. QRS: QRS duration. QTc: heart rate-corrected QT. LVEDd: left ventricular end-diastolic diameter. LVEDd/BS: left ventricular end-diastolic diameter indexed for body surface area. LVEDs: left ventricular end-systolic diameter. LVPWd: left ventricular posterior wall thickness in diastole. IVSd: Interventricular septum thickness in diastole. LVM: left ventricular mass crude. LVM/height ${ }^{2.7}$ : left ventricular mass indexed for height 2.7. LVM/BS: left ventricular mass indexed for body surface area. LVEF: left ventricular ejection fraction. 
Median SST was $7.4 \pm 3.7$ (IQR 1.0, 17.0) hours/day among Maghreb and 7.4 \pm 3.5 (IQR 1.0, 15, 0) among Blacks ( $\mathrm{p}=0.976$ ). as shown in Table 4, in Maghreb, SST was significantly associated with age, gender, heart rate, visceral obesity, waist circumference, waist-to-hip ratio, systolic blood pressure, QRS duration, crude LVM (g), LVM indexed for height (LVMIH), LVM indexed for the body surface area (LVMIBSA), LVM indexed for fat mass (LVMfm), tricuspid annular plane systolic excursion (TAPSE) and pulmonary systolic arterial pressure (PSAP). However, in Blacks, cigarette smoking and mean blood pressure (MBP) were the only parameter associated with SST. SST was not associated with any left ventricular parameter.

Table 4. Factors influenced by SST in univariate analysis.

\begin{tabular}{|c|c|c|c|c|c|c|c|c|}
\hline \multirow{3}{*}{ Variables } & \multicolumn{4}{|c|}{ BSSA } & \multicolumn{4}{|c|}{ Maghreb } \\
\hline & $1-4 h$ & $5-9 h$ & $\geq 10 \mathrm{~h}$ & & $1-4 h$ & $5-9 h$ & $\geq 10 \mathrm{~h}$ & \\
\hline & $\mathrm{n}=22$ & $\mathrm{n}=49$ & $\mathrm{n}=29$ & $P$ & $\mathrm{n}=46$ & $\mathrm{n}=85$ & $\mathrm{n}=58$ & $P$ \\
\hline Gender & & & & 0.605 & & & & $<0.0001$ \\
\hline Male & $14(63.6)$ & $30(61.2)$ & $21(72.4)$ & & $23(50.0)$ & $63(74.1)$ & $22(37.9)$ & \\
\hline Female & $8(36.4)$ & $19(38.8)$ & $8(27.6)$ & & $23(50.0)$ & $22(25.9)$ & $36(62.1)$ & \\
\hline HTN & $5 \quad(22.7)$ & $7(14.3)$ & $5(17.2)$ & 0.961 & $13(28.3)$ & $18(21.2)$ & $10(17.2)$ & 0.277 \\
\hline Heartrate (bpm) & $2(9.1)$ & $5(10.2)$ & $2(6.9)$ & 0.906 & $1(2.2)$ & $7(8.2)$ & $10(17.2)$ & 0.036 \\
\hline Obesity & $11(50.0)$ & $24(49.0)$ & $20(69.0)$ & 0.206 & $33(71.7)$ & $59(69.4)$ & $26(44.8)$ & 0.005 \\
\hline Cigarette smoking & $0(0.0)$ & $2(4.1)$ & $4(13.8)$ & 0.031 & $3(6.5)$ & $6(7.1)$ & $3(5.2)$ & 0.930 \\
\hline Alcoolintake & $0(0.0)$ & $0(0.0)$ & $2(6.9)$ & 0.129 & $1(2.2)$ & $4(4.7)$ & $1(1.7)$ & 0.579 \\
\hline Age ans & $31.2 \pm 11.5$ & $28.7 \pm 11.1$ & $26.2 \pm 9.1$ & 0.292 & $35.6 \pm 11.9$ & $32.4 \pm 10.9$ & $23.5 \pm 8.3$ & $<0.0001$ \\
\hline IMC & $23.6 \pm 4.4$ & $24.2 \pm 4.3$ & $25.6 \pm 5.3$ & 0.601 & $27.3 \pm 5.5$ & $27.3 \pm 5.8$ & $25.5 \pm 5.6$ & 0.117 \\
\hline TT Cm & $85.3 \pm 23.9$ & $81.3 \pm 12.5$ & $82.2 \pm 10.5$ & 0.339 & $89.9 \pm 11.4$ & $91.1 \pm 13.9$ & $83.2 \pm 13.7$ & 0.002 \\
\hline WHiR & $0.90 \pm 0.33$ & $0.85 \pm 0.10$ & $0.84 \pm 0.06$ & 0.629 & $0.89 \pm 0.06$ & $0.89 \pm 0.08$ & $0.83 \pm 0.08$ & $<0.0001$ \\
\hline WHeR & $0.50 \pm 0.13$ & $0.48 \pm 0.08$ & $0.48 \pm 0.06$ & 0.507 & $0.54 \pm 0.09$ & $0.54 \pm 0.09$ & $0.51 \pm 0.09$ & 0.129 \\
\hline PAS mmHg & $113.5 \pm 15.6$ & $117.9 \pm 14.9$ & $116.8 \pm 13.2$ & 0.449 & 123.717 & $122.2 \pm 14.6$ & $116.8 \pm 12.8$ & 0.040 \\
\hline PAD mmHg & $78.6 \pm 8.9$ & $76.2 \pm 11.2$ & $74.9 \pm 10.0$ & 0.871 & $79.1 \pm 10.6$ & $77.7 \pm 8.8$ & $76.3 \pm 11.1$ & 0.351 \\
\hline PAM & $90.3 \pm 10.2$ & $90.1 \pm 11.4$ & $88.9 \pm 10.2$ & 0.035 & $93.9 \pm 12.2$ & $92.6 \pm 9.3$ & $89.8 \pm 10.7$ & 0.111 \\
\hline PP & $34.9 \pm 11.6$ & $41.7 \pm 11.2$ & $41.9 \pm 9.6$ & 0.137 & $44.6 \pm 12.1$ & $44.5 \pm 12.6$ & $40.6 \pm 10.4$ & 0.108 \\
\hline Masse grasse & $18.0 \pm 6.2$ & $18.7 \pm 10.4$ & $14.5 \pm 8.3$ & 0.902 & $25.1 \pm 13.2$ & $21.9 \pm 12.7$ & $22.3 \pm 13.6$ & 0.383 \\
\hline QRS duree & $88.7 \pm 17.5$ & $91.1 \pm 23.9$ & $89.9 \pm 16.7$ & 0.843 & $101.8 \pm 17.5$ & $99.1 \pm 31.3$ & $90.6 \pm 13.3$ & 0.039 \\
\hline MVGg & $136.6 \pm 40.8$ & $132.2 \pm 37.7$ & $130.6 \pm 33.9$ & 0.753 & $145.1 \pm 34.2$ & $144.6 \pm 32.0$ & $110.5 \pm 30.7$ & $<0.0001$ \\
\hline MVGIt & $33.1 \pm 9.9$ & $32.3 \pm 10.6$ & $31.0 \pm 8.5$ & 0.440 & $36.9 \pm 9.2$ & $34.8 \pm 9.6$ & $29.4 \pm 8.1$ & $<0.0001$ \\
\hline MVG SC & $76.4 \pm 19.1$ & $73.5 \pm 18.8$ & $70.0 \pm 15.0$ & 0.286 & $79.1 \pm 16.1$ & $76.2 \pm 15.6$ & $63.3 \pm 12.8$ & $<0.0001$ \\
\hline MVG mgr & $9.7 \pm 3.9$ & $9.2 \pm 4.3$ & $7.9 \pm 3.5$ & 0.072 & $7.8 \pm 3.9$ & $7.9 \pm 4.0$ & $7.2 \pm 3.4$ & 0.584 \\
\hline MVG mm & $4.9 \pm 1.5$ & $4.5 \pm 1.1$ & $4.1 \pm 0.9$ & 0.809 & $5.0 \pm 1.1$ & $4.7 \pm 1.1$ & $3.8 \pm 0.7$ & $<0.0001$ \\
\hline FEVG & $64.6 \pm 13.7$ & $65.0 \pm 6.9$ & $66.2 \pm 9.3$ & 0.402 & $67.2 \pm 5.9$ & $65.2 \pm 6.7$ & $65.8 \pm 6.9$ & 0.258 \\
\hline EPR & $0.34 \pm 0.06$ & $0.36 \pm 0.06$ & $0.37 \pm 0.09$ & 0.516 & $0.34 \pm 0.06$ & $0.34 \pm 0.05$ & $.32 \pm 0.05$ & 0.141 \\
\hline $\mathrm{Sa}$ & $15.9 \pm 6.2$ & $14.2 \pm 1.9$ & $14.4 \pm 3.1$ & 0.184 & $16.5 \pm 3.4$ & $14.9 \pm 7.2$ & $17.1 \pm 3.8$ & 0.577 \\
\hline TAPSE & $26.3 \pm 4.9$ & $25.0 \pm 3.5$ & $24.1 \pm 4.1$ & 0.447 & $26.2 \pm 4.1$ & $23.9 \pm 5.1$ & $26.4 \pm 8.9$ & 0.039 \\
\hline SOG & $20.8 \pm 6.6$ & $18.6 \pm 5.4$ & $20.6 \pm 5.2$ & 0.870 & 18.15 & $18.4 \pm 3.1$ & $21.5 \pm 9.1$ & 0.119 \\
\hline IMT mm & $0.49 \pm 0.11$ & $0.48 \pm 0.11$ & $0.49 \pm 0.14$ & 0.447 & $.47 \pm 0.12$ & $0.48 \pm 0.14$ & $0.49 \pm 0.14$ & 0.882 \\
\hline Glycémie & $83.1 \pm 23.8$ & $88.8 \pm 15.0$ & $89.3 \pm 14.4$ & 0.693 & $88.5 \pm 16.5$ & $91.3 \pm 11.5$ & $97.7 \pm 17.0$ & 0.190 \\
\hline PAPS & $21.1 \pm 3.7$ & $22.1 \pm 5.4$ & $22.0 \pm 5.1$ & 0.263 & $24.3 \pm 4.9$ & $21.9 \pm 4.5$ & $20.0 \pm 4.3$ & $<0.0001$ \\
\hline
\end{tabular}


In the Maghreb, there was a statistically significant association between SST and LVM with higher screen time being associated with smaller LVM $(\mathrm{P}<$ 0.001). After adjusting for the different confounding factors in multivariate analysis, the association between SST and LVM persisted in Maghreb (Table 5).

\section{Discussion}

This is, to our best knowledge, the first population-based study that addresses the issue of the interaction of ethnicity in the association between sedentary behavior and left ventricular mass in the African continent.

The main finding of this study is the existence of an association between sedentary screen time and LVM in the Maghreb, a white skin African ethnic group, in whom higher screen time is associated with smaller LVM, an association that did not emerge among Black sub-Saharan Africans.

The existence of an association between sedentary and left ventricular mass in the white race and the non-existence of it in the black race has recently been reported by Bethany et al. in the CARDIA study [13]. In the same study, Bethanie reported a higher screen time associated with larger LVM, whereas in the present study we found a higher screen time associated with smaller LVM. This inverse association between sedentary and LVM found in this study is consistent with the results reported by Jeroen et al. [16] which demonstrated for the first time that LV dimensions were smaller in a sedentary adults population with intellectual and concomitant physical disability compared to controls.

The cardiovascular consequences of sedentary would be related to cardiovascular risk factors including obesity and insulin resistance. However, the NHANES data showed the existence in the white race of an association between sedentary and cardiovascular risk factors, including obesity, which does not seem to exist in the black race [12]. This would explain the absence of association between sedentary and LVM observed in Black subjects recruited in this

Table 5. Factors influenced by SST in multivariate analysis.

\begin{tabular}{ccccc}
\hline & $\begin{array}{c}1-4 \mathrm{~h} \\
\mathrm{n}=46\end{array}$ & $\begin{array}{c}5-9 \mathrm{~h} \\
\mathrm{n}=85\end{array}$ & $\begin{array}{c}\geq 10 \mathrm{~h} \\
\mathrm{n}=58\end{array}$ & $\mathrm{p}$ \\
\hline Age (years) & $0.91(0.84-0.97)$ & $0.97(0.91-1.03)$ & $1.3(1.11-1.38)$ & $<0.001$ \\
Gender & $6.5(1.46-29.3)$ & $5.5(1.14-9.73)$ & $7.3(1.06-12.00)$ & $\mathbf{0 . 0 2 4}$ \\
Heart rate & $5.3(0.31-92.3)$ & $6.6(1.16-10.17)$ & $8.6(1.34-756)$ & $\mathbf{0 . 0 0 5}$ \\
Waist & $1.1(0.94-1.2)$ & $0.97(0.89-1.07)$ & $0.99(0.87-1.14)$ & 0.962 \\
circumference (cm) & & & & \\
WHiR & $0.12(0.01-2.09)$ & $18.0(1.02-21.11)$ & $83.3(1.59-97.04)$ & $\mathbf{0 . 0 0 6}$ \\
SBP mmHg & $1.1(0.96-1.3)$ & $0.96(0.91-1.01)$ & $1.03(0.95-1.1)$ & 0.504 \\
QRS duration & $2.1(0.98-3.1)$ & $1.01(0.99-1.02)$ & $3.03(0.97-6.04)$ & 0.872 \\
LVM (g) & $3.6(1.93-5.97)$ & $5.9(1.91-11.03)$ & $9.04(1.95-13.13)$ & $\mathbf{0 . 0 4 0}$ \\
LVMIH & $5.9(1.94-8.38)$ & $7.1(1.86-9.19)$ & $8.8(1.62-11.10)$ & $\mathbf{0 . 0 1 9}$ \\
LVMIBSA & $3.9(1.68-6.68)$ & $5.1(1.81-12.25)$ & $7.15(1.83-15.59)$ & $\mathbf{0 . 0 3 4}$ \\
TAPSE & $0.95(0.90-1.02)$ & $1.1(1.04-1.23)$ & $0.95(0.86-1.04)$ & $\mathbf{0 . 0 2 1}$ \\
PAPS (mmHg) & $0.88(0.8-1.01)$ & $1.01(0.93-1.08)$ & $1.1(1.02-126)$ & 0.227 \\
\hline
\end{tabular}


study and in that of Bethany. The pathophysiological explanation of this racial difference in the repercussion of sedentary in terms of cardiovascular risk factors remains to be elucidated. It would hide behind the complex entanglement of signaling pathways involved in the physiology of myocardial plasticity.

If the results of this study converge with those of Bethanie on the existence of an association between sedentary and LVM in Whites and not in Blacks, they diverge as to the meaning of this association. Indeed, Bethanie reports that higher sedentary screen time is associated with greater LVM [13], while we found the opposite: the higher the sedentary screen time, the smaller the LVM.

How can this divergence be explained? Presumably that everything depends on the complex interactions between the indirect reverberation of sedentary on LVM via cardiovascular risk factors that tend to cause myocardial hypertrophy, and direct repercussion by adaptation response of the myocardium to reduced load, to cause a myocardial atrophy, as demonstrated in bed rest or deconditioning studies [17] [18].

This study suffers from the weakness of being transversal and therefore unfit to postulate any causal link. Other studies are therefore needed to elucidate the cardiovascular impact of sedentary, since it is potentially modifiable.

\section{Acknowledgements}

The authors gratefully acknowledge Mr. CISSE KalilouPapa, president of the CESAM and Mr. Sharif Zian, Secretary General of the Office of the Cady Ayyad University Students for their kindly facilitated the recruitment and mobilization of participants. The following people also accept the expression of gratitude to the authors of this work for their active and voluntary participation in the survey. These gentlemen Wetchi Adolphe, Louis Kyungu, IssaImbongo, Harouna Mbaka and Djuma Nkubokoso. A special thanks is sent to the PAC Association (Physicians Accros Continents) through its Secretary General Dr. Saad Ali Al-Qarni for their partnership with the Faculty of Medicine of University of Kinshasa and for funding Dr Kianu Phanzu Bernard Training in the Service of Cardiology of CHU Mohammed VI of Marrakech.

\section{Author Contributions}

Design and concept of study: Annis Charifa. Acquisition of data: KianuPhanzu Bernard, Annis Charifa, Sidibe Moussa; Manuscripti draft: Kianu Phanzu Bernard. Supervision: Kintoki Vita Eleuthère, Longo-Mbenza Benjamin, M'buyamba Kabangu, Benzaroual Dounia, El Hattaoui Mohammed. All authors read and approved the final manuscript.

\section{References}

[1] Eaton, S.B. (2006) The Ancestral Human Diet: What Was It and Should It Be a Paradigm for Contemporary Nutrition? Proceedings of the Nutrition Society, 65, 1-6.

[2] Gibbs, R.J., Schelbert, E.B., Craft, L.L., Sidney, S., Lima, J. and Lewis, C.E. (2014) Se- 
dentary Screen Time and Left Ventricular Structure and Function: The CARDIA Study. Medicine \& Science in Sports \& Exercise, 46, 276-283.

[3] Wijndaele, K., Besson, H., et al. (2011) Television Viewing Time Independently Predicts All-Cause and Cardiovascular Mortality: The EPIC Norfolk Study. International Journal of Epidemiology, 40, 150-159.

[4] Stamatakis, E. and Dunstan, D.W. (2011) Screen-Based Entertainment Time, AllCause Mortality, and Cardiovascular Events: Population-Based Study with Ongoing Mortality and Hospital Events Follow-Up. Journal of the American College of Cardiology, 57, 292-299.

[5] Patel, A.V., Deka, A., et al. (2010) Leisure Time Spent Sitting in Relation to Total Mortality in a Prospective Cohort of US Adults. American Journal of Epidemiology, 172, 419-429.

[6] Warren, T.Y., Hooker, S.P., Sui, X., Church, T.S. and Blair, S.N. (2010) Sedentary Behaviors Increase Risk of Cardiovascular Disease Mortality in Men. Medicine \& Science in Sports \& Exercise, 42, 879-885.

[7] Katzmarzyk, P.T., Craig, C.L. and Bouchard, C. (2009) Sitting Time and Mortality from All Causes, Cardiovascular Disease, and Cancer. Medicine \& Science in Sports \& Exercise, 41, 998-1005.

[8] Matthews, C.E., Moore, S.C., et al. (2012) Amount of Time Spent in Sedentary Behaviors and Cause-Specific Mortality in US Adults. American Journal of Clinical Nutrition, 95, 437-445.

[9] Dunstan, D.W., Healy, G.N., et al. (2010) Television Viewing Time and Mortality: the Australian Diabetes, Obesity and Lifestyle Study (AusDiab). Circulation, 121, 384-391.

[10] Bluemke, D.A., Lima, J.A.C., Liu, K., Olson, J., Burke, G.L. and Folsom, A.R. (2008) The Relationship of Left Ventricular Mass and Geometry to Incident Cardiovascular Events. The MESA (Multi-Ethnic Study of Atherosclerosis) Study. Journal of the American College of Cardiology, 52, 8.

[11] Vakili, B.A., Okin, P.M. and Devereux, R.B. (2001) Prognostic Implications of Left Ventricular Hypertrophy. American Heart Journal, 141, 334-341. https://doi.org/10.1067/mhj.2001.113218

[12] Healy, G.N., Matthews, C., Dunstan, D.W., Winkler, E.A. and Owen, N. (2011) Sedentary Time and Cardiometabolic Biomarkers in US Adults: NHANES 2003-06. European Heart Journal, 32, 590-597. https://doi.org/10.1093/eurheartj/ehq451

[13] Gibbs, B., Reis, J.P., Schelbert, E.B., Craft, L.L., Sidney, S., Lima, J. and Lewis, C.E. (2014) Sedentary Screen Time and Left Ventricular Structure and Function: The CARDIA Study. Medicine \& Science in Sports \& Exercise, 46, 276-283. https://doi.org/10.1249/MSS.0b013e3182a4df33

[14] Cleland, C.L., Hunter, R.F., Kee, F., Cupples, M.E., Sallis, J.F. and Tully, M.A. (2014) Validity of the Global Physical Activity Questionnaire (GPAQ) in Assessing Levels and Change in Moderate-Vigorous Physical Activity and Sedentary Behaviour. BMC Public Health, 14, 1.

[15] Lang, R.M., Badano, L.P., Mor-Avi, V., Afilalo, J., Armstrong, A., Ernande, L., Flachskampf, F.A., Foster, E., Goldstein, S.A., Kuznetsova, T. and Lancellotti, P. (2015) Recommendations for Cardiac Chamber Quantification by Echocardiography in Adults: An Update from the American Society of Echocardiography and the European Association of Cardiovascular Imaging. Journal of the American Society of Echocardiography, 28, 1-39.

[16] Vis, J.C., de Bruin-Bon, R., Bouma, B.J., Backx, A.P., Huisman, S.A., Imschoot, L. 
and Mulder, B.J. (2012) The Sedentary Heart: Physical Inactivity Is Associated with Cardiac Atrophy in Adults with an Intellectual Disability. International Journal of Cardiology, 158, 387-393. https://doi.org/10.1016/j.ijcard.2011.01.064

[17] Perhonen, M.A., Franco, F., Lane, L.D., Buckey, J.C., Blomqvist, C.G., Zerwekh, J.E., Peshock, R.M., Weatherall, P.T. and Levine, B.D. (2001) Cardiac Atrophy after Bed Rest and Spaceflight. Journal of Applied Physiology, 91, 645-653.

[18] Spaak, J., Montmerle, S., Sundblad, P. and Linnarsson, D. (1985) Long-Term Bed Rest-Induced Reductions in Stroke Volume during Rest and Exercise: Cardiac Dysfunction vs. Volume Depletion. Journal of Applied Physiology, 98, 648-654.

https://doi.org/10.1152/japplphysiol.01332.2003

Submit or recommend next manuscript to SCIRP and we will provide best service for you:

Accepting pre-submission inquiries through Email, Facebook, LinkedIn, Twitter, etc. A wide selection of journals (inclusive of 9 subjects, more than 200 journals)

Providing 24-hour high-quality service

User-friendly online submission system

Fair and swift peer-review system

Efficient typesetting and proofreading procedure

Display of the result of downloads and visits, as well as the number of cited articles

Maximum dissemination of your research work

Submit your manuscript at: http://papersubmission.scirp.org/

Or contactwjcd@scirp.org 